never complained of these pains before the operation), so I recommended the nurse to give them gentle massage. The patient was unable to stand this, owing to the tenderness of her bones. I may remark here that the nurse remained with her two months after the operation, making a total continuous two months after the operation, making a total continuous walking about for some time it was noticed by both herself and the nurse that her legs were becoming bowed, and that she was shorter in stature than she had been before the operation. On December 24 th, 1907, the same nurse was again summoned, as the patient had an attack of oedema of the lungs, and she observed that the disease was progressing, the femora and tibiae having become still more bowed. In December, 1908, the same nurse was called to attend the patient's husband, so once more she had an opportunity of seeing the patient, and she then observed a marked advance in the changing condition of the affected bones. In May, 1909, the patient's husband died somewhat suddenly, causing a severe shock to the patient. The nurse returneil to her as companion and attendant for a period of six weeks. She again noticed how the osteitis had progressed and she also noticed how much shorter the patient had become. At one time (before the operation) she was equal to, or even taller than her daughter; now she was many inches shorter. She had great difficulty in walking, and when she did so her She had great difficulty in walking, and when she did so her
body seemed to be tilted forward on her hips. She also complained frequently of pain in her thighs and legs.

A curious incident now occurred. On February 27th, 1911, the patient, while alone in one of the bedrooms, mounted a pair of steps in order to hang some curtains, when a thud was heard followed by groans. When the daughter entered the room she found her mother lying on the floor in a dazed condition, and quite unable to explain how the accident had happened; the last thing she remembered was standing on the steps. 'There last thing she remembered was standing on the steps. There were no broken bones, and all I could discover on examination
was a pair of sluggish pupils. The patient complained of yain all over her body, but more especially on the left side. She was able, with an effort, to move all her limbs. In the course of a day or two it became apparent that she had fallen on her left side, as bruises began to make their appearance, and I was able to detect a slight left hemiplegia. Added to this she occasionally had attacks, during which she talked quite incoherently, and had diplopia. There had evidently been a slight herently, and had diplopia. There had evidently been a slight then followed unconsciousness, and hence her fall. The patient made a fair recovery from this attack, but became more helpless in getting about.

On May 10th, 1911, the same nurse was requisitioned for an illness of the patient's unmarried daughter, so that once more there was a favourable opportunity of witnessing the prosress of the disease. One day the nurse saw her standing in her bedroom, partially undressed. She described her thus: "Her feet were close together, but her legs were far apart; the body was tilted far forward on the hips; her chest was more contracter than formerly, and her shoulders seemed broadened and rounded." On May 16th the patient was stooping to put out a gas-ring, when her left femur suddenly gave way, and as she fell to the floor she realized that the bone was fractured. Endle chloroform I was able to get the ends of the bone well together and the limb was put up in a Liston's long splint and three small and the limb was put up in a Liston's long splint and three small that the bone was in good position. There was now no doubt of the diagnosis; the femora were much enlarged and bowe forward and outward, and the tibiae were also bowed in the sam direction, but not nearly so proportionately enlarged. When the patient lay on her back with her heels together the knees were widely separated, and there was an arch under the centre of the right femur under which one could pass one's hand. The cranial bones were not enlarged as one would have expected, but the lower maxilla was thickened and protuberant at the but the lower maxilla was thickened and protuberant at the
chin. The course of the illness from this date forward was also of a somewhat exceptional character. For three week the evening temperature oscillated between $99^{\circ}$ and $101^{\circ}$, at the end of which time the temperature became normal for a fortnight. Coincident with this change was a most altcred condition of mind. The patient became wandering, restless and delusional, and at times did not know those about her. On May 25th she began to feel sick. The tongue was perfectly clean, and there was no stomach trouble. The next three days she could keep nothing down, returning even the iced water she took, so had to be fed rectally. Her pulse became quick and compressible. Dr. Horder kindly met me in consultation on June 13th. There was no pneumonia but symptoms of a failing heart. She now took a turn for the better, and kept down an ounce of whey with twenty drops of brandy every hour. She was quite unconscious or incolierent till June 17th, whel she suddenly had a lucid interval. I was sent for immediately and was able to get her to sign her will, which she had liad drawn up the very day her fracture had occurred. In the evening of that day her senses were preternaturally alert she expressed great relief at having signed her will, and for the tirst time for many years (for she was chronically deaf) she distinctly heard the birds singing and her children's voices in the garden. The next two days her mind was still exceedingly active, though the period of hyperacusis had passed. On the evening of June 20th the temperature suddenly ran up to 104? evening of June 20 th the temperature suddenly ran up to 104 ? ascend dnring the day to $102^{\circ}$, about which level it remained till June 25 th, when she passed away at 4.15 a.m.

The interest of this singular case rests in the following facts: first, that the whole life of the osteitis deformans could be traced from onset to exit; secondly, that no cranial bone was affected except the chin-point of the lower maxilla, to which allusion has already been made; and lastly, that the onset of this disease immediately followed an operation for appendicitis. Whether this last was merely a coincidence, or whether the general shock of the operation affected the patient's nervous system in such a way as to produce a trophic degeneration in the bones of the lower extremities, it is, of course, impossible to say. No autopsy was made, but it was discovered after death that though the ends of the bone had been placed and kejt together in excellent position for a period of six weeks all but two days, no sound union had been establisherl. as the lifting of the leg produced cracking and bending of the affected femur.

\section{TESTS OF INTELLIGENCE.*}

By W. A. POTTS, M.A., M.D.,

IAAT: MLDICAL INVESTIGATOR TO THE ROYAL COMMISSION ON THI CARE AND CONTROL OF THE FLEBLE-MINDLD.

L.sst year in one of our local medical societies an inter. esting paper was read on Certificates of Lunacy, the writing of which may devolve on the majority of us at any time. $\Lambda$ paper dealing with tests of intelligence will perhaps be equally useful. In a cortificate of lunacy facts indicating insanity at the time of examination are reguircd: many of the tests I shall describe furnish facts of this kind, and may establish a diagnosis; they wo lld not suffice for a patient with a fixed delusion, if there wcre no intellectual impairment; nor could they command the attention of a case of acute mania. In many lunacy certificates, however, they are useful, and also in other circumstances where a certificate of mental capacity is required ; for instance, when a person contemplates making a peculliar will, or wishes to make a will of any kind when he is suffering or has suffered from disturbance of the mental health. In such cases explaining the provisions and effects of the will, and enumerating all the near relations, with the reasons for ignoring some or ail of them, may constitute an ample justification for the certificate required, and it may be neither necessary nor wise to proceed further. On the other hand, certificates may be strengthened by the statement that certain tests were quickly and accurately performed. Sometines it is important to have available definite evidence of this kind.

A note should always be kept of the tests nsed, but it is usually wiser not to give details till one is asked for full particulars, or is called into court. The legal mind, versed in the difference between statutory right and wrong, does not always understand that partial lack of intelligence and control may constitute irresponsibility, but is often satisfied by the explanation that certain suitable tests could not be performed.

Till recently there have been scarcely any satisfactory schemes for testing intelligence; the ordinary investigator merely examined the capacity for reading and writing, for elementary calculations, and asked one or two simple questions, such as the day of the month and the name of our King, without much regard to the agc, previons training, or environment. During the last few years, however, the Report of the Royal Commission on the Care and Control of the Feeble-minded, the large amount of propagandist work some of us have accomplished, and the institution of medical inspection in schools, have focussed the attention alike of the public and the profession. Laist summer, both at the National Conference on the Prevention of Destitution and at the meeting of the British Association, papers on mental tests were read. So many have been suggested that the ordinary medical man is a little perplexed as to which system to choose, especially as some schools claim that theirs is the one reliable method, and certain authorities, after issuing a final scheme, have introduced considerable modifications. Let me say at once that it does not do to pin one's faith to any single scheme; it is necessary to study several, and use the best tests from each as occasion demands.

In this paper I do not propose to discuss the diagnosis of amentia and dementia. I would, however, remind you that stigmata of degeneration are not without value, and

A paper read at the Birmingham Branch of the British Medical Association on Novembor 9 th, 1911. 
that the appearance, manner, carriage, and gait are of supreme importance. Indeed, as I have often pointed out, the attitude of a patient towards a mental test. and his behaviour during and after the execution of it, are frequently of more importance for diagnostic purposes than the fact whether he did it correctly or not. Those patients who realize their shortcomings are the more hopeful. A child who scribbles aimlessly, on being asked to write a word, is more defective than one who admits he cannot. It is not possible to orerrate the importance of a thorough physical examination in every mental case, and of a reliable family and personal history. Indeed, as regards many congenital defectives who come before us when young adults, the number of situations they have passed through, seven or eight in a year at the least, and the small amount of the best wages earned, almost determine the whole matter.

The environment and opportunities must always be considered. The child who told me that the family cat was an animal with four legs which clrank beer, was not neces. sarily wrong according to his experience. Nor was s. boy of 12 who could not rearl mentally defective; really he, or at any rate his father, was particularly sharp, for they had eluded the school attendance officer's for vears; even when I put the anthorities at once on their track the couple had agrain ramished.

The tests I am going to describe are not adapted for the deaf or rlumb, nor for those who are partially aftlicted in that way, nor for those with severe visual defects. Those are possible explanations of a parent mental defect which must be excluded by examining the hearing and visual power and the condition of the throat. In his report for 1909 the school medical ofticer for Wimbledon drew atten. tion to 107 children two or more standards below the arerage for their age; only four of these were mentally defective. In twenty-four the eyesight was defective, while thirty were from very unsatisfactory homes; they were ill-nourished, undersized, and neglected.

Those who attend to all the points I have indicated will appraise at their true value the results of tests of intelligence. These tests have their limitations; we are on the right tack. however, in evolving and using definite systems; we are then better able to sas, not merely that a child is backward, bat how backward he is. and how far he will improve with training. After an ordinary examination a rood working prognosis can often be given, but there will be fewer mistakes if we use a clefinite measuring scheme rather than continue a mode of investigation which at the best was unscientitic. Some of the tests are also of use in difficult cascs. such as moral defectives. where we are quite satisficil ourselves but camnot otherwise write down cridence which will convince the lavman and the lawyer. They are valuable, too, for recording the progress of lumatics; as dementia increases. instead of saying that the intelligence, power of initiation. and other capacities appear to be failing, we can write the patient down as Standard II one vear and standard $N$ the next. When a case of melancholia is under treatment, it is more satisfactory to measure the improvement than merely say ". the patient appears to be better.'

The first set of tests are those of Dr. Sante de Sanctis, Professor of Experimental Psych slogy in the Cniversity of liome; these are good tests, few in number-six-and such that any one can use then in an ordinary examination.

lirst T'st ifive balls, about $2 \mathrm{in}$. in diameter, of different colours-red, green, blue, yellow, and purple).-Give me a ball. (Note time of respe ins?; then cover up the balls.)

Second Test.-Which is the ball you gave me: (Note time of response.)

Third Test.-Do you see this piece of wood: (A cube with $1: 2$ in. sides.) Show me all that are like it in that sroup. (A group of five cubes, tliree pyramids, and two parallelepipeds.) (Note time of response.)

Fourth Test.-On this card (a card with ten rows of fourteen figures each, the figures being a triangle, an oblong, and a square placed at randons) mark every figure that you can find like this (a cube). (Note time, errors, and omissions.)

Fith Test (twelve cubes rarying from 1 to $3 \mathrm{in.}$.).-Here are blocks of wood like what you saw on the card.

(i) How many are there? (Child allowed to count.)

(b). Which is the largest?

(c) Which is the one farthest from you?

(Note time, errors, and omissions.)
Sirth Te'st.-Four questions :

1. Are large things hearier or lighter than small things:

2. How does it happen that sometimes small things are lieavier than large ones?

3. Do distant things look larger or smaller than near ones?

4. Do they only appear smaller, or are they smaller?

Of course, the patient must be put at his ease; it is best to treat the procedure as a game. Rest a little after each test. A question may be repeated three times; no response then is failure.

An additional advantage of these tests is that we can classify by the results, thus-

1. There is a high degree of intellectual defect when the patient does not get beyond the second question.

2. There is a moderate degree of defect when he does the fifth with difficulty and many errors.

3. There is a mild degree when he fails at the sixth only.

4. A child who does all with normal rapidity is not defective.

The wext test-Kraepelin's reckoning test-which is useful for measuring the action of tea, alcohol, and drugs, which affect mental processes, is often more useful for checking the progress of a case of melancholia than for diamnosis.

'The original test was to add a large number of figures together as rapidly as possible; the latest modification used at Munich by Professor Kraepelin is to have a book like a school copybook. Each page has 10 columns, and each column 36 digits. In order to economize space, and at the same time make the test a little more complicated, the digits are added in pairs, the second of the pair being linked with the next, so that each digit except the first is 1 sised twice. The sum of each pair is written down on the right hand side, only the units figure being put down if the sum exceeds 9. Thus-

$\begin{array}{ll}3 & \\ \mathbf{4} & \mathbf{7} \\ \mathbf{8} & \mathbf{2} \\ \mathbf{6} & 4 \\ \mathbf{9} & 5 \\ \mathbf{2} & 1\end{array}$

The patient must first be carefully instructed: then, after a few seconds" warning, the order to start is oiven. At the end of each minute the examiner calls "Strolie", the patient then makes a dash und(re the last sum, and rees on aoain as hard as he can: the test continues for fifteen minutes. The examiner then adds up the number of sums, counts the corrected and uncorrected errors, and what is more important, counts the number of sums done in each successive minute. From the latter records we often get definite evidence of the unduly rapid onset of fatigue in an exhausted or abnormally constituted brain.

The most important system is that of Binet. Binet: tests are open to criticism; some of them are too difficult, and the standard has been fixed too much by school records rather than by an estimate of success in ordinary life. All the same the series is excellent; it is most comprehensive, and will appeal particularly to the school medical officer who is not working against time, because with these tests the cliild can at once be placed exactly. Gorldard. the energetic medical superintendent of the New Jersey Training School at Vineland, after trying it carefully in 400 mentally defective children and 2,000 normal ones-a stupendous task-and correlating his results by other methods, expresses unqualified approval. He merely points out that one or two of the tests as clesigned in France must be modified for our countrymen. We owe a clebt of gratitude to Binet, not because all his tests are original (for many are not); but for systematizing and standardizing as he has done. It is, however, too elaborate a system for the ordinary practitioner, who will do well to pick ont some of the most useful. I will give only a few tests illustratice of Binet's method. ${ }^{1}$

${ }^{1}$ Those who wish to so into the system in detail can either study Binet's papers, published in $L$ Annee psychologique and elsewhere;
perhaps moxe conveniently the excellent compendium of Croddard.. 
ST2 MEF PRTTRR

TESTS OF TNTELLIGENCE:
The latest authorized rersion consists of five tests for rach rear of life from 3 to 15: when user for actults we class them as 4-year-olds, or whaterer their standard may be. The principle is that the tests for each year are such that a nomal child of that age can accomplish them, while a younger one cannot: the system was erolver by ". studying normal children and tinding out what they can do. and pieking ont of all those things those that are so fundanental and human that they do not depend upon training.

Binct and simon in 1906 proposed thirty tests. in which no aceount was taken of the ase of the child or of his training. In a paper publisher in 1908 they evolved a set of tents for each age of the child and nearly climinated the element of training. presenting therefore "' a measuring scale for initelligence." "This has been morlified again. and the same number of tests five introduced for cach age. If a child suceeces in all the tests for his age he is normal : if only for a real younger he is backwarl to the extent of one vear: if he is more than three years backwated he is montally defectire. Before his stambarl is settled. howerer. a correction must be made. The child must be advancer one year for avery fire higher tests in which he suceceds. For cximple. a 9-vear-old child fails in two of the 9-rear-old tents: he ajpears, therefore. to be only 8 nentally. On futher examination. howerer, he deres three of the 10-year-old tests: these. added to the three of the 9.rear-olil ones he had already ilone. malse -ix in ail: he is therefore adranced a rear and classed as nomal. We begin with the tests for the age of the chilk. or the age we think he is mentally.

'Tests for' a 3-rear-cld child:

1. The child is asked to point to its nose, its eves. and its mouth.

2. He repeats a sentence of six syllables for example, . It rains. I an hungry.

3. He repeats two figures, 7. 2 : the figures being pro. nounced distinctly. one half-second apart. without emphasis on cither.

4. He is asked lis family name.

5. He is shown a picture.

Binet uses three pictures, the essentials of which are that they represent a situation, but contain only one or two objects and one or two figures. I have not repro luced Binet's pictures: I use two. one of which eontains things familiar to Birningham children.

First Picture... wooden cradle on a river in flood. containing a baby and a kitten.

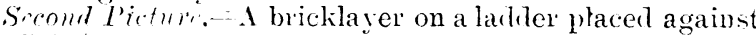
ricalding.

A child of 3 can only name the things in the picture: he camot describe any actions. The pictures are userl again as a test at 7 rears, and the child is then expected to describe the situation.

It lonr lenrs he is asked if he is a boy or a girl, to recognize three familiar objects (a knife, a ker. a penny to repeat three figmres. and to compare two lines itwo parallel lines $3 \mathrm{~cm}$. apart. one $5 \mathrm{~cm}$.. the other $6 \mathrm{~cm}$.) which is the longer line: Hesitation in this test counts as failure.

It Fire From he has to compare two weights of equal sire and appearance, to copy a square with ink. to count four pennies in a row. and to make the two halves of a card cut along the diagonal into a figure like an uncut art.

It ri, Yinrs. amoug other testi. comes the one of acsthetic comparison, "Which is the prettier." " Binet uses six heads of women in pair's, the one pretty, the other not. He also tries the exerution of three simultaneous commissions: " Do you see this kev") Put it on that chair. Then shut the loor. Ifter that, bring me the box that is on the chair."

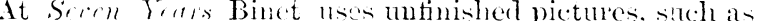
heads with the eves. nose, or mouth not drawn in. "What is wanting in that picture?" He also makes the child count thinteen pemies place in a row ; each pemny must be touched with the finger at the same time as the child names the number.

It lighlet berse a child should be able to comt backwards from twenty to one in twenty seconds without making more tlan one mistake, and shonld be able to compare two things from memory. such as a butterfly and a fly.

At. Nin lurr's he is tested with weights. and at Ten
Tors with questions of comprehension. "What ought rou to do when you have bioken something that does not belong to you :." "It least twenty seconds are allowed for: an answer. and only three out of fire such questions need be answered correctly.

It Vileren Vears we say to the child, " I am going to tell vou a sentence in which there is nomsense. You listen rarefully and see if yon can tell me where the nonsense i..." Then we read reig slowly:

1. "An unfortmate crelist has harl his head broken and is dead from the fall : they hare taken him to the homital. and they do not think that he will recover:"

2. " The police foumd restriday the body of a vomus wirl cut into eightern pieces. They believe that she killed herself."

sime people object to these horrors but children and the mentally defectire usmally revel in them. It the same age-11 - Binet tells a child to say as many words as possible in three minutes. such as " table. board. shirt. carriage." This is an excellent tent. At least 60 worils must be given. some get to 200.

At Turlee lears Binet aslis for simple rhymes, and the

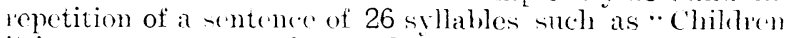
it is necessaly to work rery hard for a living: you must go crerr moning to your school " and so the teists go om. Those I have rescribed are some of the frincipal ones.

Abelson is the first worker'. as far as I know. in thicountry who has becen able to derote the time necessity to carry ont similar investigations on a large scale. 11 , has evolved a small mumber of tests of his own; he aimat corvelating the results by the degree of competence for work in the ordinary world rather than by school recorrs. One of his principles is that the results must be marken either by time. or for accuracy, but never in both ways: in most of them he uses a stop-watch, and so long as the child is working accurately urges him to go faster. but checks him when the work is inaccurate. The patient is placed by his time iecord. In practice I have foumel some of liis methods ristinctly nseful. but hare not ret harl an opportunity of trying them on a large scale. i)r. Abelson has most lindly supplied ne with certain details. The chicf tests are-

Talping.- The child is given a pointed instrument. and told to tap as fast as possible for ten seconds inside a $3 \mathrm{in}$. surare on a piece of paper. The first attempt is for pre. paration. the -econd and third are recorded.

Crossing out libing. An irregnlarly disposed line ot small rings. Thee attempts. second and third recorded.

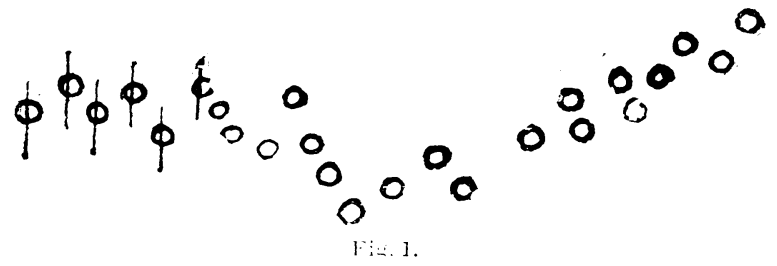

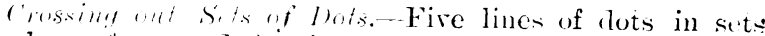
of three. fons. and five in any order. The child is toli to cross out all the fours as quickly as possible. There attemptis as betore.

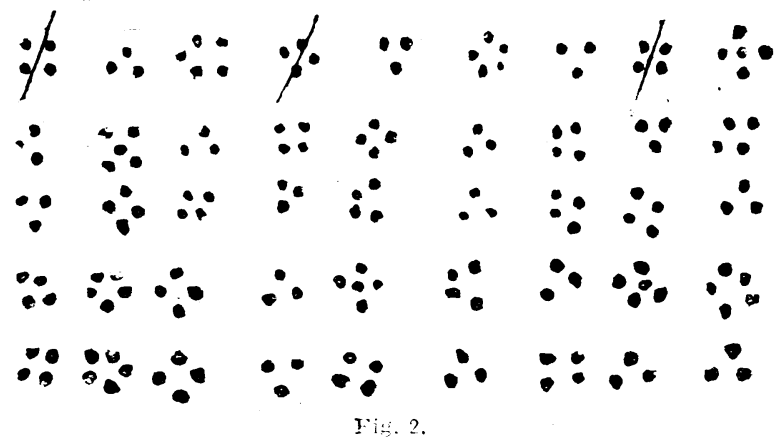

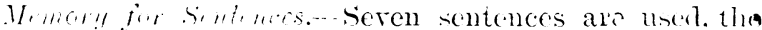
first a thort one and each of the other's a little longer than the preceding: markis accotding to accuracy.

There is aloo a momory for names test and a menory for commistions test: in the latter the later commissions are rerv complicaterl-for example, "Put the book the 
sancer, and the penknife upon the gas-stove, then put the brush next to the spoon, then go and open the door, then sit down on the armchair, and then get up and put the matches which are on the table inside the matchbox."

There is a discrimination of lengths test, and one or two others before reaching the tests with geometrical figures. For these tests the child is practised for a week in recognizing a triangle, a circle, and a square; he is then provided with several sheets on which two or more of these figures are drawn, the figures frequently overlapping. There is a different colour for each of the three figures. The figures are then covered and the child is given an order, such as "Point inside both circles," or "Point in the triangle and square but not in the circle," according to the drawing he has at the moment. Each order is given twice carefully, making sure the child understands; the figure is then uncovered and the stop-watch started. If it is done incorrectly, the figure is covered and the order given again; the time taken in this case is added to that taken in the first instance. Abelson has eighteen geometrical figure tests; they promise to be of considerable value.

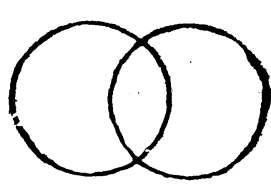

Fig. 3.

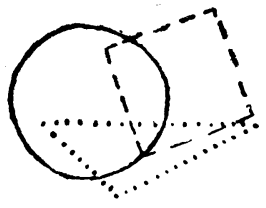

Fis. 4.
An excellent single test recommended by Tredgold is to s snd a mentally defective person to open a locked door, the key being hung on the wall just by the door. An intelligent child will use the key, a mentally defective one will come back and say he cannot open the door. A mentally defective child or adult, if told to hold out his hand or put out his tongue, frequently maintains the position till told to desist.

I could describe many other useful tests; I lave explained sufficiently, however, the lines upon which we may work to try and obtain facts which will corroborate our opinion as to the presence or absence of mental defect.

\section{ARREST OF SEVERE EPILEPSY IN A CHILD AGED FOUR.}

By J. STEWART MACKINTOSH, M.D.DERH., M.R.C.S., L.R.C.P. HAMPSTEAD.

I тнгік the following case worth recording in cletail, because it affords clear evidence that it is not necessary to abandon hope in a case of ingravescent epileptic habit that cloes not yield promptly to routine treatment.

The child was born on Mareh 4th. 1906. I attended the mother in her confinement, and induced labour at the beginning of the ninth month at the suggestion of Dr. Herman, who saw the mother early in her pregnancy for retroversion of the gravid nterus, and judiced that labour would prove difticult at term uterus, and judged that labour would prove difticult
from the size of the child. He weighed $8 \mathrm{lb}$. when born.

from the size of the child. He weighed $8 \mathrm{lb}$. when born.
The child was breast-fed for two months, and, the materna milk then failing, he was bottle-fed with cliluted cow's milk, cream, etc., with ocrasional raw meat juice, on which be throve till 9 months old. About this time the family left London for the country. He was fed on Savory and Moore's fool till 2 years old, and the mother then gave him " grary and bread, puddings, etc.," and a little later added finely-chopped raw meat to his diet, which therefore from the age of 9 months consisted chiefly of soft farinaceous foods, according to the present custom of of soft farinaceous foods, according to the present custom of feeding young children. However, up to the age of 25 he was precocious for his age and restless in temperament.

In Angust, 1908, the mother came up to London to be attended by me in her fourth confinement. When she returned home two months later she found a marked change in the child for which no cause could be ascribed by those she left in charge. He had become irritable and spiteful towards his nurse and two elder brothers (both of whom were healthy children); he hail also become very frightened of the trains which ran near his house, though formerly they delighted him. During the ensuing vear he suffered from "gastric attacks" which appeared to have been due to carbohydrate dyspepsia, anc the change in temperament continued.

In the spring of 1909 he was twice bitten bra chainet bulldog and suffered a severe nervous shock. Following this he grew shy of strangers and said passers-by "looked at him."
He would no longer play with his brothers, and would carry on conversations with the moon, the rain, or the wind. In September, 1909, he was seized with a characteristic epileptic fit when playing on the golf course. It lasted about ten minutes. The fits recurred three or four times daily. He was seen by a doctor, who prescribed potassium bromide gr.v t.d., and was examined by sir Vietor Horslev for a possible focal lesion, with negative results. Sir Victor Horsley thought the prognosis unfavourable. The potassium bromide checked the fits for six weeks, after which they returned. He was then seen by a well-known specialist in diseases of children, who also thought the outlook grave, but suggested that his enlarged tonsils and adenoid growths should be removed. This was accordingly done, the tonsils being enucleated by Mr. Waugh.

No immediate benefit as regards the fits resulting, a neurologist who has made a special study of epilepsy was consulterl He also was not hopeful of the future, but recommended a tria of Gélineaux's dragées, which contain potassium bromide, picrotoxin, and antimony. This did not, however, improve the fits. which had increased (possibly temporarily) in number after the operation, and, on the mother giving on her own responsibility two dragées at a time instead of one, the seizures rose in number to thirty per diem. The mother now despaired of a cure, and brought the child to me asking if I could think of any other procedure likely to improve matters. In view of the history of "gastric attacks" I cut down the carbohydrate history of "gastric attacks" I cut down the carbohydrate
element in the diet to a minimum, and prescribed the folelement in the diet to a minimum, ${ }^{*}$ and prescribed the fol-
lowing mixture to be taken thrice daily: Sodium bromide gr.iv, strontium bromide gr.ij, tincture of belladonna miv, orange flower water to $z \mathrm{ij}$, and also urged that the child should live in the country unier the quietest possible conditions. Small doses of calomel were also given for a few dars.

The result far exceeded my expectations, for from this time (September, 1910) onwards the fits rapidly diminished in intensity, though not at first in number, until they became imperceptible. At Christmas, 1910, the child showed some symptoms of atropism with visual hallucinations, and, becoming frightened, had two slight fits. On cutting out the belladonna from the prescription no further fits occurred, except on one occasion, when after a fright a single attack occurrecl. But apart from these interruptions, the child has been free from fits for ten months; he has no gastric trouble, and his mother reports his temperament has changed again to that of a normal, if somewhat excitable, child, and his intellectual progress, which came to a standstill, if not worse, with the onset of the fits, has resumed its due advance.

I do not think the arrest of the fits should be ascribed offhand to a lucky combination of drugs. The removal of "adenoids" has at times been attended with success, though not necessarily immediate, after drugs have failed. I believe there was a source of irritation in the carbo. hydrate dyspepsia with which adenoids are frequently associated. A child with nasal obstruction can only make four chews on an average between each breath, as he is using his mouth for respiration as well as mastication, whereas the normal child bites his mouthful fourteen to twenty times before gulping the bolus.

The mere removal of the adenoids and tonsils is, how. ever, not always sufficient to cure the digestive troubles. The child's mastication requires re-education in order to deal with his carbohydrates, and there appears to be in some cases a chronic infection of the colon, subject to recurrent exacerbations, which requires treatment before the source of irritation can be removed. It is worth noting that in this case the tonsils were totally ablated, as it is now, of course, well known that the stump of a guillotined tonsil may still be a source of infection of the alimentary tract if sufficient tissue be left.

As regards drugs, the sodium and strontium salts were selected in case the failure of potassium bromide was due to idiosyncrasy. The occasional value of belladonna when bromides have failed is well known. Orange flower water had much repute on the Continent as an antispasmodic before bromides came into ase, and cures of epilepsy have been ascribed to its use as a simple. The value of " antispasmodics" comes in as a check to the "habit" after the original source of irritation has been removed.

It is of course difficult to forecast what the fnture may liare in store for the child whose case I have set fortl. Some writers on epilepsy draw a strong line of demarcation between "essential" and "accidental " epilepsy, assigning the former term to cases in which, with a strong family history, fits arise without apparent provocation in children clull of intellect, unexcitable, commonly dark in complexion and sallow of skin ; the epithet " accidental" being reserved for those cases in which the child is of highly neurotic temperament and the fits are traceable to a definite preclisposing and frequently maintaining cause.

An excellent account of the range of dietary suitable in carbo hydrate dyspepsia is found in The Child's Diet (Curgenren). Lewis and co. 1905. Is. 6d. 